known processes. This I hold to be a radically vicious hypothesis, not merely because it is unverifiable (for, in spite of the dictum of J.S. Mill, that appears to be an insufficient ground for condemnation), but ( 1 ) because it invokes an agency of an absolutely unknown order, (2) because it is not necessary and does not help us to give a consistent description of the facts, (3) chiefly because it serves merely as a cloak disguising our ignorance and must tend to make those who adopt it content to remain ignorant. Dr. Schofield's position seems to be based solely on the following argument:-

The human organism exhibits activities that cannot be shown to be accompanied by corresponding states or processes of consciousness, but which nevertheless display so great a complexity and nicety of adjustment of means to ends that we cannot suppose them to be carried out by the agency of neural processes only; therefore we must assume an agent that plays a part similar to that which we assign to consciousness, but differing from it merely in not being consciousness. But when many of our leading thinkers accept the view so clearly enunciated by Huxley in his essay on "Animal Automatism," the view, namely, that all human activities are carried out by the agency of neural processes without the causal intervention of any other factor, consciousness being an epiphenomenon merely, why should Dr. Schofield believe himself competent to draw a line at any particular degree of complexity of behaviour, saying "So much can the unaided neural processes accomplish, but no more."

W. $\mathrm{MCD}$.

\section{THE UNIVERSITY OF LIVERPOOL.}

I N 1879, Dr. Lightfoot, speaking at a prize-giving in Liverpool, described as seen in a dream its future University College. The speech had no small influence in securing the foundation of the College, and twentythree years have done much to realise the dream.

The progress of University College has been most striking ; it started in $188 \mathrm{I}$ with seven professorships and three lectureships. Now there are twenty-one professorships each endowed with the sum of ro,oool. and one temporarily endowed. The total number of professors, lecturers and assistants is seventy-two, and the value of the endowment about 226,000 l.

Practically all of this has been given by citizens of Liverpool, much in single sums of 10,000 ., for the founders, inspired by $\mathrm{Mr}$. Rathbone, were wise men, and realised that they were providing for a large need and must do it on a large scale.

The value of the College site and buildings already erected is about $280,000 l$., while $50,000 l$. from the fund recently raised is to be spent immediately in further buildings. For scholarships, prizes, the maintenance of laboratories and of the Day Training College, about $60,000 l$. has been invested; a capital sum of more than $600,000 l$., contributed in twenty-three years by Liverpool benefactors for the advancement of learning and for the education of their townsfolk.

Besides this, large sums are given voluntarily each year for annual expenditure. The city shows its interest in a practical manner by the grant it makes towards certain of the technical classes, while the fees received from students last year reached 13,000 . These results, though they may seem small compared with some of those achieved through individual generosity in America, are splendid. The Bishop's dream is nearly realised.

Now the men who have done this come forward and say that it is necessary for the future success of their work that the union which exists between the three colleges of the Victoria University should be dissolved, and that Liverpool should have its own University. Can anyone gainsay their right to speak or urge that they are not the best judges of their case?

They speak with no uncertain voice. The Education Bill transfers to the City Council the control of education in the city, and the Council is of opinion that a University of Liverpool is necessary as the key. stone of the arch it intends to build; it has already NO. I7 29 , VOL. 67$]$ received power to raise a rate for university education if a Charter is granted to University College, and it intends to do it. It is inconceivable that that Charter should be refused, that the Government, which has indicated its wise desire to leave freedom wherever possible for the development of education according to local needs, should refuse the request of one of the greatest of the local authorities of the country, the Corporation of Liverpool, to complete its work by establishing a "great university for a great city." These were the words used by Mr. R. B. Haldane at a city dinner in Liverpool some four years since; it was clear from their reception then that the ideal he put forward appealed strongly to the representative gathering which he addressed, and in the joint petition of the City and University College for a Charter which is now before the Privy Council we have the outcome of his words.

The case is one which carries conviction.as it is read. The grant, it is urged, would greatly stimulate the development and increase the influence of University College and other institutions for the promotion of higher education in the city; it would bring higher education into closer connection with the professional and commercial life of the city; it would provide a true university education for many who cannot leave home to obtain it - the promoters urge with success the distinction between education in a university college, a part of a federal university, and that in a university-it would stimulate research by multiplying in the proper places the centres at which this can be carried on, and, having regard to the inadequate provision of the higher forms of education in England relatively to foreign nations, would be for the benefit of the nation as a whole.

Each of these claims is substantiated by solid facts.

The success of the movement will mean the dissolution of the Victoria University in its present form.

To this, Owens College, the predominant partner in the federal University, has given a ready consent; the two great cities of south-west Lancashire are at one in the belief that each may well be the centre of an independent university, and the case for Owens College is in many ways stronger than that for Liverpool. Yorkshire College, on the other hand, wishes to retain the present system. The financial position of Yorkshire College is much weaker than that of her sister colleges; Mr. Lupton at Leeds in January last said, when speaking of the number of its students, "It will compare favourably and creditably with the other two colleges of the University, but in its material assets it is ludicrously wanting. In the capital of the College, the assets are between $250,000 l$. and $300,000 l$, , but the money has been spent on buildings, apparatus, \&c. Of invested capital, we have not quite $39,000 /$., the income of which goes to the annual expenditure of the College."

At present, then, Yorkshire College is less fitted than the others to become a university, hence in part its dislike at being left alone. But Yorkshiremen are quite able, as was stated by the Principal of the College and the Bishop of Ripon at the same meeting, to create a university of their own if the need for it arises, and it will be found in Leeds no less than in Liverpool that a great university is a great power for good and for advancement.

To Liverpool and Manchester, the failure of the petition would be disastrous ; it would curb enthusiasm, it would check the flow of benefactions for education, it would discourage men whose whole heart is in the great work they have set themselves to do, to build in each of these two cities a university which they feel is needed for the highest training of men and women in whose hands the future rests; it would compel two responsible bodies who have each decided that it can best perform its allotted duties separately to endeavour to struggle on in a union which they feel is hopeless.

All this is clear to anyone reading the case presented, so clear that of the issue there can surely be no doubt. 